Supplement of Geosci. Model Dev., 13, 521-536, 2020

https://doi.org/10.5194/gmd-13-521-2020-supplement

(C) Author(s) 2020. This work is distributed under

the Creative Commons Attribution 4.0 License.

(c) (1)

Supplement of

\title{
Implementation of a roughness sublayer parameterization in the Weather Research and Forecasting model (WRF version 3.7.1) and its evaluation for regional climate simulations
}

Junhong Lee et al.

Correspondence to: Jinkyu Hong (jhong@yonsei.ac.kr)

The copyright of individual parts of the supplement might differ from the CC BY 4.0 License. 
Table S1-: Statistics of the $10 \mathrm{~m}$ wind speed, $2 \mathrm{~m}$ temperature, and rain rate in July 2016 . The top statistics are presented in bold.

\begin{tabular}{lcr}
\hline \hline & rCTL & rRSL \\
\hline $\mathbf{1 0}$ m wind speed & & \\
\hline Mean bias $\left(\mathrm{m} \mathrm{s}^{-1}\right)$ & 2.10 & $\mathbf{2 . 0 1}$ \\
Root mean square error $\left(\mathrm{m} \mathrm{s}^{-1}\right)$ & 2.74 & $\mathbf{2 . 6 9}$ \\
& & \\
$\mathbf{2}$ m temperature & & -1.68 \\
\hline Mean bias $(\mathrm{K})$ & $\mathbf{- 1 . 3 5}$ & $\mathbf{2 . 5 5}$ \\
Root mean square error $(\mathrm{K})$ & 2.37 & \\
Rain rate & & \\
\hline Mean bias $\left(\right.$ mm $\left.^{-1}\right)$ & & 0.150 \\
Root-mean-square error $\left(\mathrm{mm} \mathrm{hr}^{-1}\right)$ & $\mathbf{0 . 1 2 2}$ & $\mathbf{2 . 9 4 8}$ \\
Pattern correlation & 2.964 & $\mathbf{0 . 8 8 9}$ \\
\hline
\end{tabular}



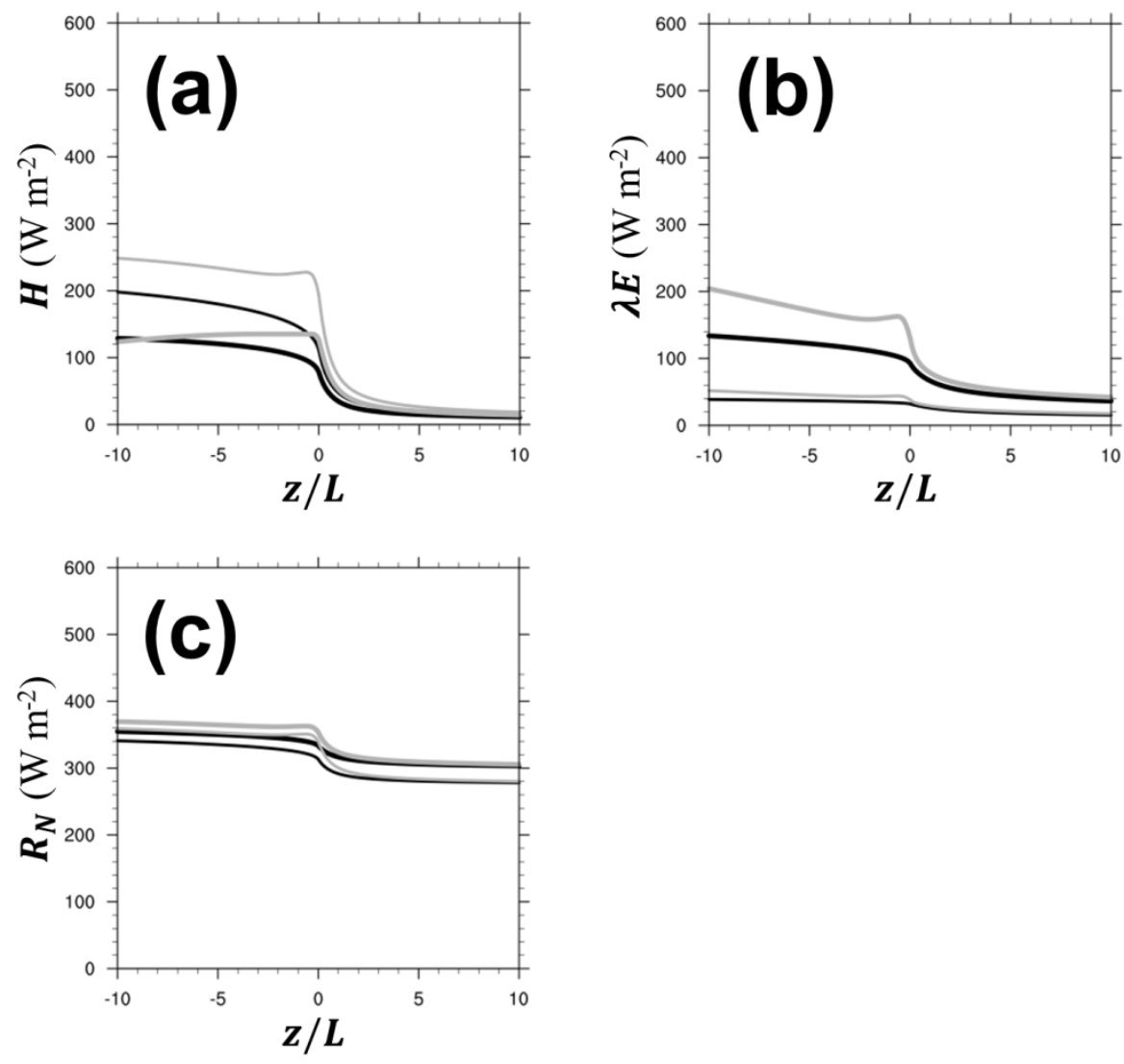

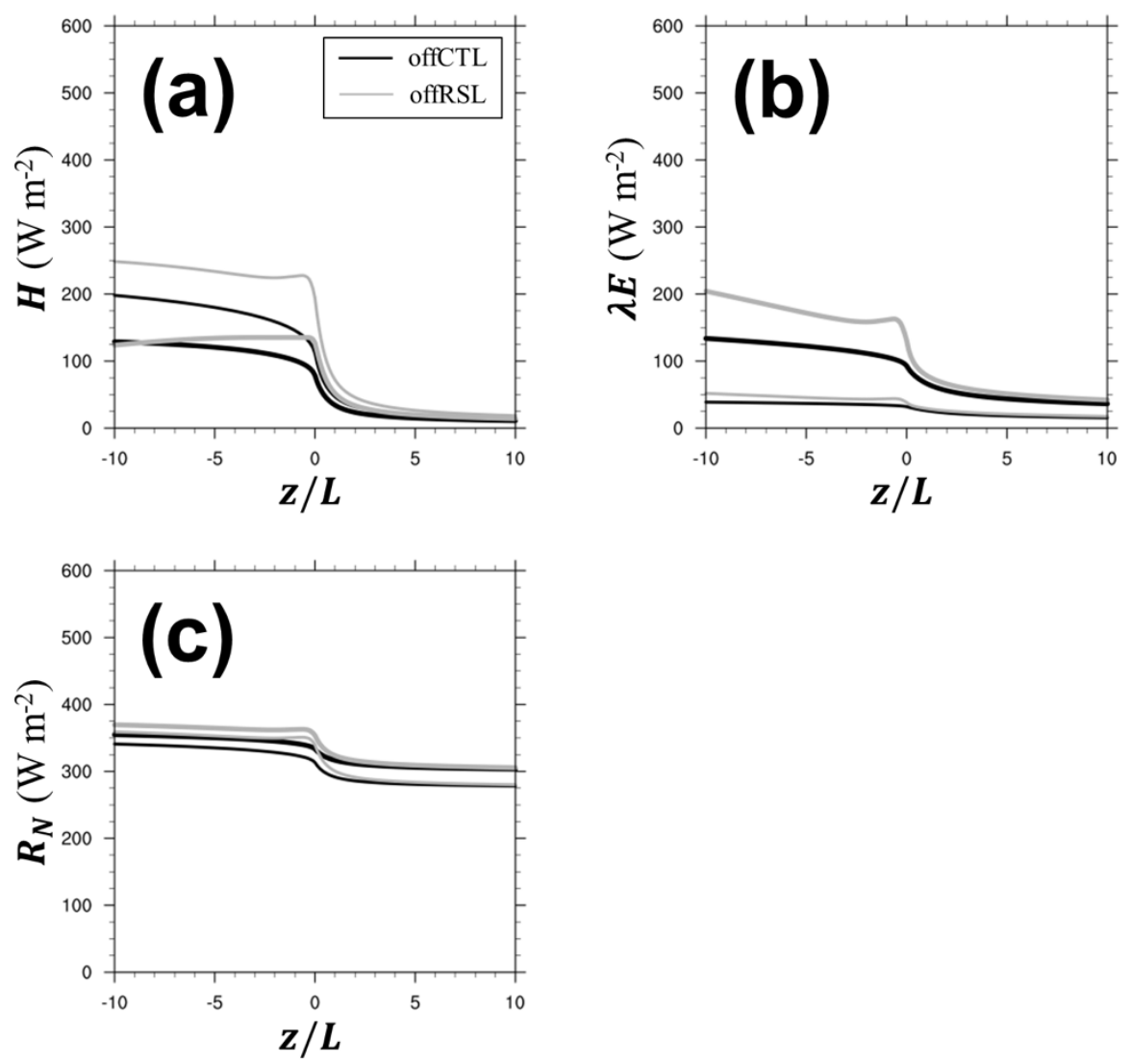

Figure S1:- (a) sensible heat flux $\left(\mathrm{W} \mathrm{m}^{-2}\right)$, (b) latent heat flux $\left(\mathrm{W} \mathrm{m}^{-2}\right)$, and (c) net radiation $\left(\mathrm{W} \mathrm{m}^{-2}\right)$ at a given atmospheric stability $(z / L)$. The black lines denote offCTL, while the gray lines denote offRSL. Thin and thick lines correspond to soil moisture of $0.15 \mathrm{~m}^{3}$ $\mathrm{m}^{-3}$ and $0.15 \mathrm{~m}^{3} \mathrm{~m}^{-3}$, respectively. 
rCTL
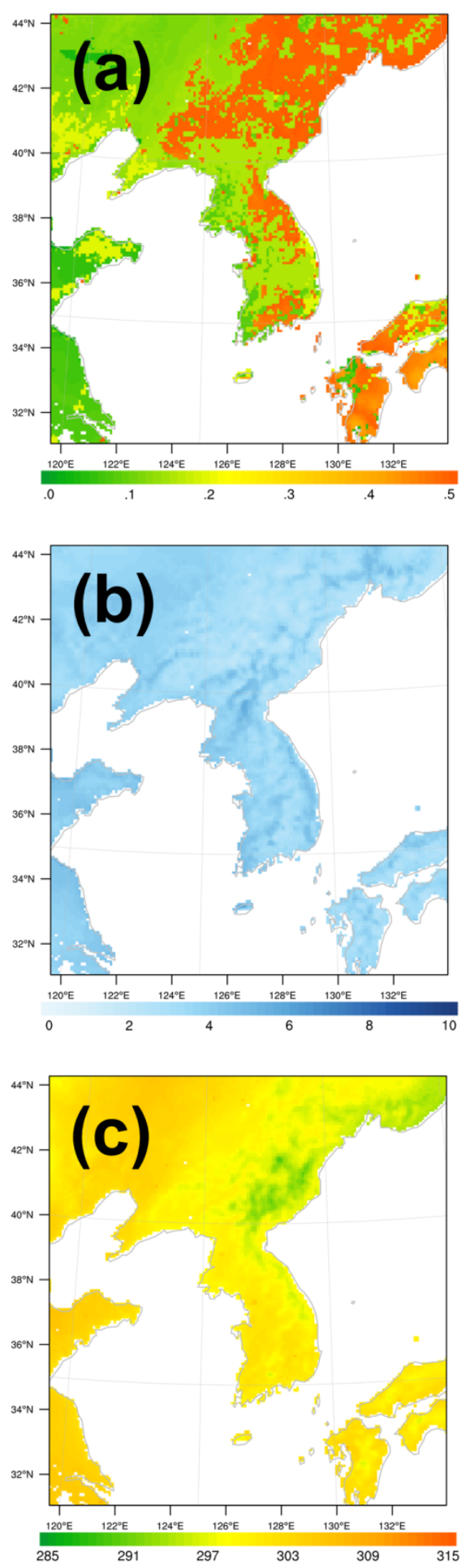

rRSL-rCTL
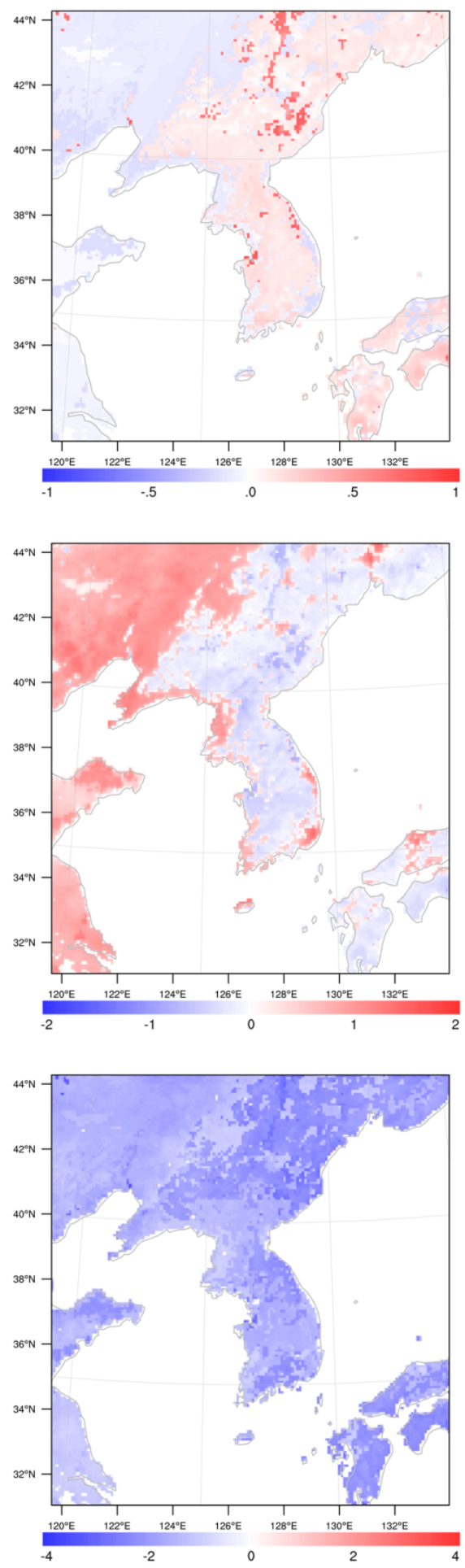
Figure S2:- (a) Roughness length (m), (b) $10 \mathrm{~m}$ wind speed $\left(\mathrm{m} \mathrm{s}^{-1}\right)$, and (c) daytime $2 \mathrm{~m}$ temperature (K) of the (left) $\mathrm{rCTL}$ experiment and (right) the difference (rRSL - rCTL). The results are averaged over a period of one month in July 2016 and masked out over the ocean. 

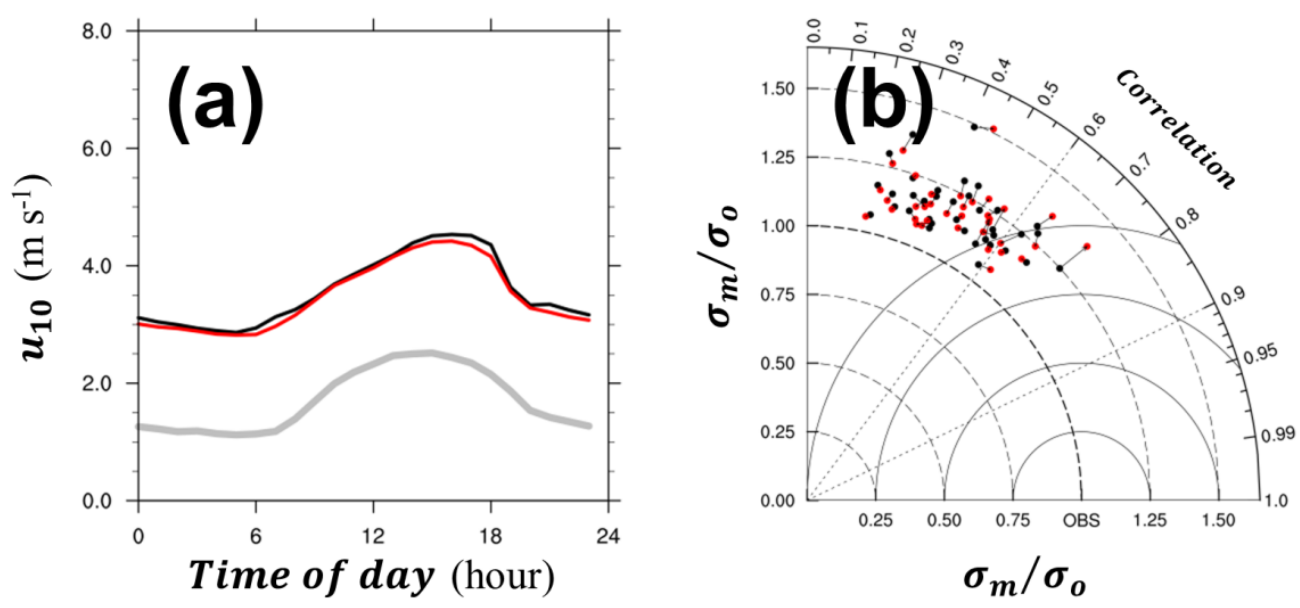

15
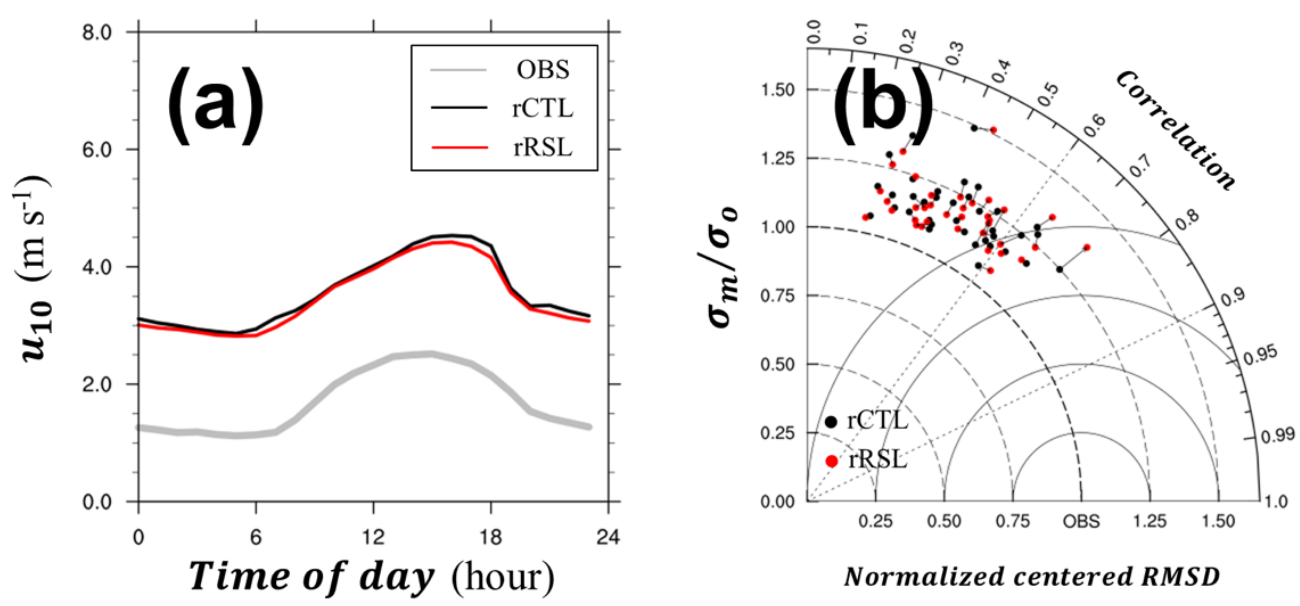

Normalized centered RMSD

Figure S3:- (a) One month mean diurnal variation of $10 \mathrm{~m}$ wind speed and (b) the Taylor diagram showing the correlation coefficient, normalized centered root-mean-square differences (RMSD), and standard deviations of the models $\left(\sigma_{m}\right)$ normalized by that of observation $\left(\sigma_{o}\right)$ from observation (gray), rCTL experiment (black), and rRSL experiment (red) in July 2016. The vectors indicate the changes of the statistics from rCTL to rRSL. The arrows indicate those from rCTL to rRSL. Every vector shows the movement toward the observation, thereby suggesting the model improvement. 

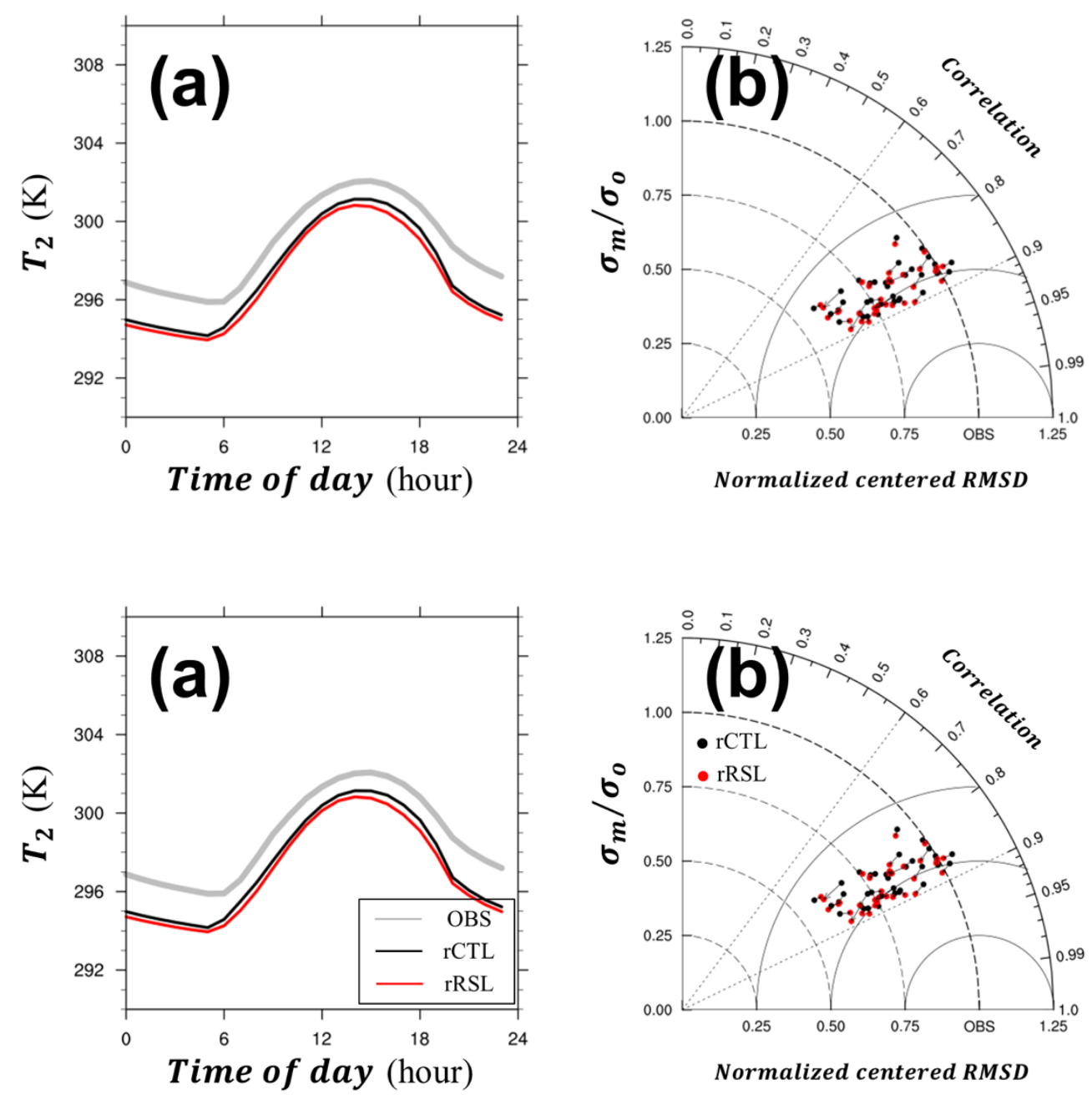

25 Figure S4:- Same as in Fig. S3 but for $\mathbf{2} \mathbf{m}$ temperature in July, 2016. 
rCTL
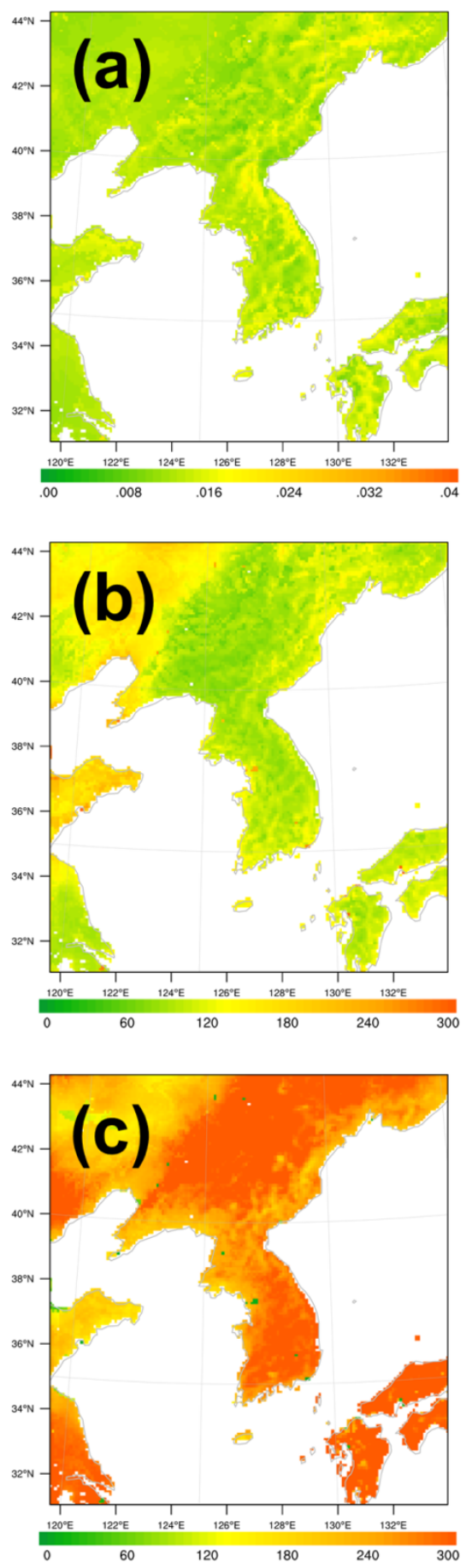

rRSL-rCTL
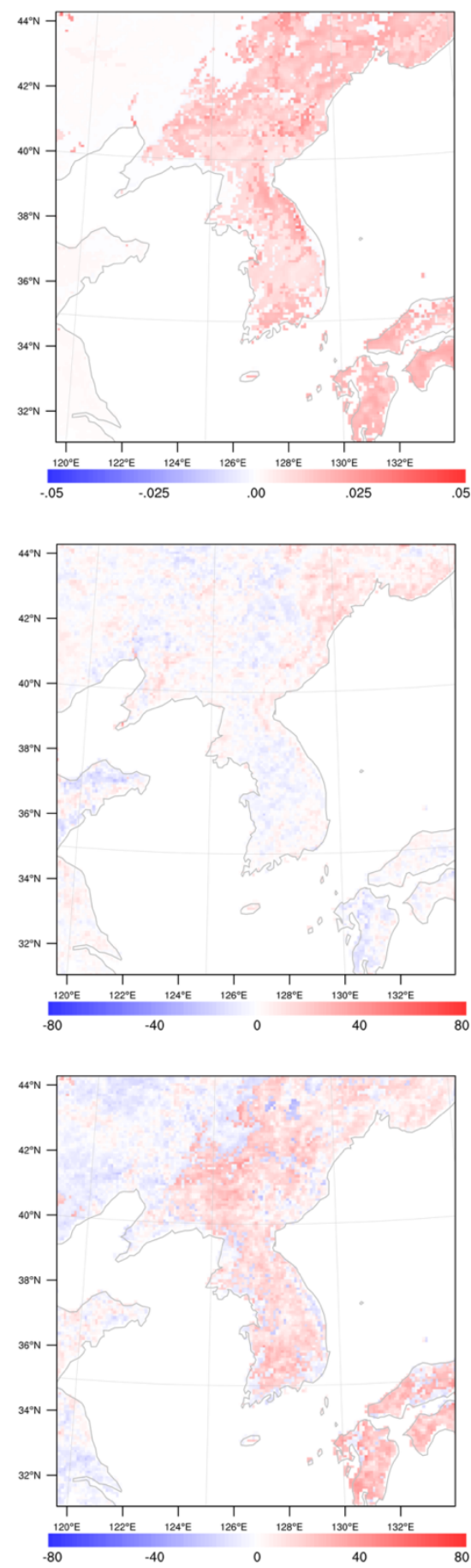
Figure S5:- (a) Aerodynamic conductance $\left(\mathrm{m} \mathrm{s}^{-1}\right)$, (b) daytime sensible heat flux $\left(\mathrm{W} \mathrm{m}^{-2}\right)$, and (c) daytime latent heat flux $\left(\mathrm{W} \mathrm{m}^{-2}\right)$ of the (left) rCTL experiment and (right) the difference (rRSL - rCTL). The results are averaged over a period of one month in July 302016 and masked out over the ocean. 

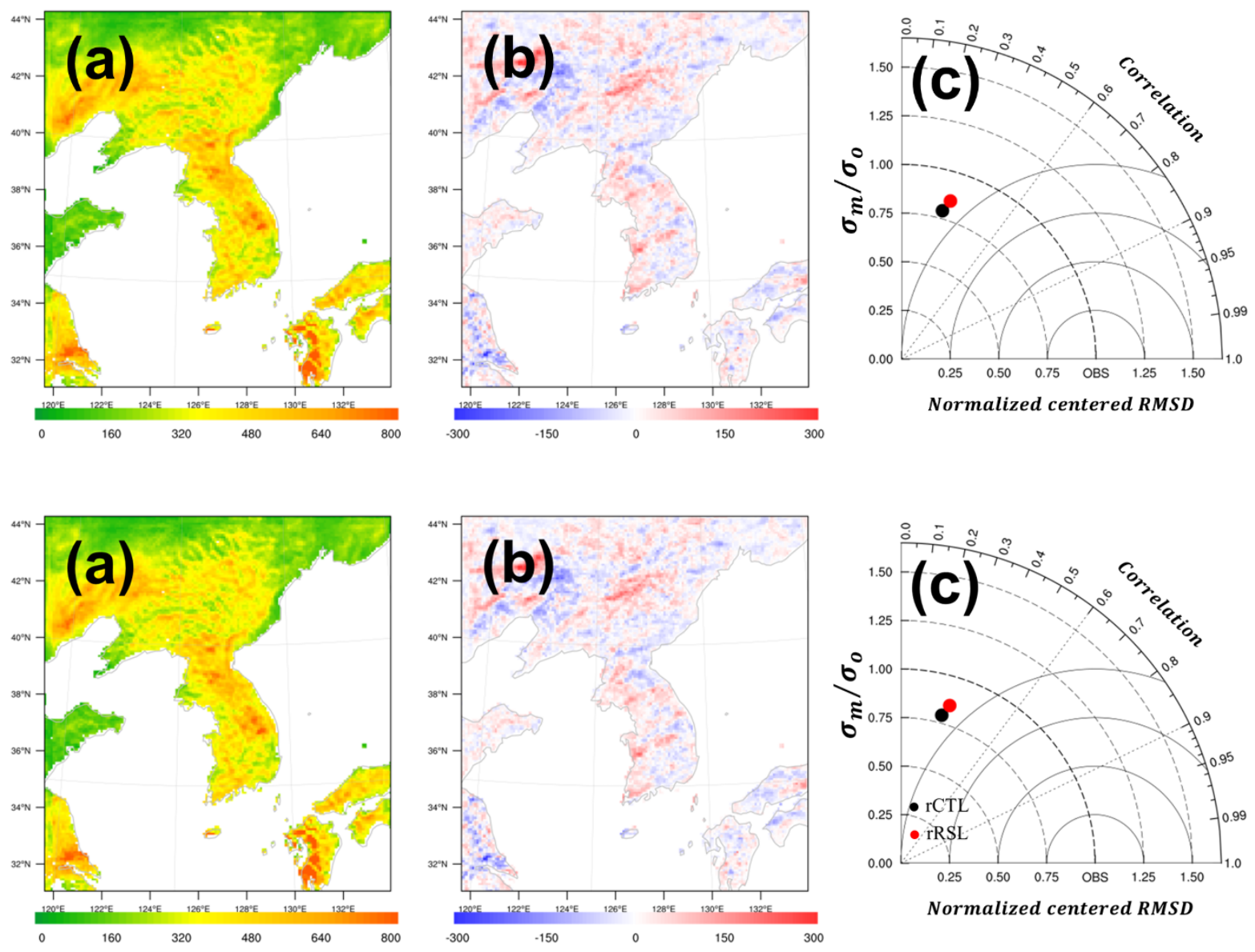

Figure S6:- (a) One month accumulated precipitation of the rCTL experiment (mm) and (b) difference (rRSL - rCTL) in July 2016.

(c) Taylor diagram showing the correlation coefficient, normalized centered root-mean-square difference (RMSD), and the standard deviations of models $\left(\sigma_{m}\right)$ normalized by that of the observation $\left(\sigma_{o}\right)$ and from the rain rate $\left(\mathrm{mm} \mathrm{h}^{-1}\right)$ of the $\mathrm{rCTL}$ experiment (black) and the rRSL experiment (red) during one month at 656 rain gauges. 